\title{
Modeling of daily body weights and body weight changes of Nordic Red cows
}

\author{
P. Mäntysaari*1 and E. A. Mäntysaari† \\ ${ }^{*}$ Milk Production, and \\ †Biometrical Genetics, Green Technology, Natural Resources Institute Finland (Luke), FIN-31600 Jokioinen, Finland
}

\begin{abstract}
Increased availability of automated weighing systems have made it possible to record massive amounts of body weight $(\mathrm{BW})$ data in a short time. If the $\mathrm{BW}$ measurement is unbiased, the changes in BW reflect the energy status of the cow and can be used for management or breeding purposes. The usefulness of the BW data depends on the reliability of the measures. The noise in BW measurements can be smoothed by fitting a parametric or time series model into the BW measurements. This study examined the accuracy of different models to predict BW of the cows based on daily BW measurements and investigated the usefulness of modeling in increasing the value of BW measurements as management and breeding tools. Data included daily BW measurements, production, and intake from 230 Nordic Red dairy cows. The BW of the cows was recorded twice a day on their return from milking. In total, the data included 50,594 daily observations with 98,418 BW measurements. A clear diurnal change was present in the BW of the cows even if they had feed available $24 \mathrm{~h}$. The daily average BW were used in the modeling. Five different models were tested: (1) a cow-wise fixed second-order polynomial regression model (FiX) including the exponential Wilmink term, (2) a random regression model with fixed and random animal lactation stage functions (MiX), (3) MiX with 13 periods of weighing added (PER), (4) natural cubic smoothing splines with 8 equally spaced knots (SPk8), and (5) spline model with no restriction on knots but a smoothing parameter corresponding to a fit of 5 degrees of freedom (SPdf5). In the original measured BW data, the within-animal variation was $6.4 \%$ of the total variance. Modeling decreased the within animal variation to levels of 2.9 to $5.1 \%$. The smallest day-to-day variation and thereafter highest day-to-day repeatabilities were with PER and MiX models. The usability of modeled BW as energy balance (EB) indicator were evaluated by estimating relationships between $\mathrm{EB}$, or EB indicators, and modeled BW change. In all cases
\end{abstract}

Received March 6, 2015.

Accepted June 18, 2015.

${ }^{1}$ Corresponding author: paivi.mantysaari@luke.fi the modeling increased the correlation and thus the reliability of the BW measurements. From all of the tested models, the best predictive value was attained by the random regression model with fixed and random animal lactation stage functions. Based on results, modeling of BW significantly increases the usefulness of BW as an EB predictor and management indicator. Key words: body weight, function smoothing, modeling, dairy cow

\section{INTRODUCTION}

The BW of the cow changes depending on the stage of lactation (Koenen et al., 1999). In the beginning of lactation insufficient feed intake and the genetic drive for high milk production leads to mobilization of energy from body reserves (Mäntysaari et al., 2010, 2012). This leads to a decrease in BW. Later in lactation, with increased feed intake and decreased milk yield, the lost body reserves are gained back, leading to an increase in BW.

Even though a reasonable period of negative energy balance (EB) at the beginning of lactation is acceptable for today's high-producing cows, deep and long-lasting negative EB can cause health and reproduction problems (de Vries et al., 1999; Collard et al., 2000). One way to cope with the development of metabolic stress and health problems related to prolonged negative EB is to consider postpartum EB in a selection goal in the breeding program. This requires measurements of EB from large population of animals. Calculation of EB based on energy input and output $\left(\mathbf{E B}_{\text {inout }}=\right.$ energy intake - energy required for milk and maintenance) requires knowledge of milk production and composition, feed DMI, BW, and the energy density of the diet. At the farm level, these measurements are difficult to measure. Further, in calculation of $\mathrm{EB}_{\text {inout }}$, considerable error can accumulate because of use of standard estimates for energy requirements (DiCostanzo et al., 1990; Chwalibog, 1991).

If the BW could be measured accurately, the change in BW should reflect the energy status of the cow and therefore the change in BW could be used as an EB indicator. For example, in the study of Coffey et al. (2001) and Friggens et al. (2007) the EB was calculated 
based on the changes in BW and BCS by converting the BW changes into weights of body lipid and protein. In the study of Mäntysaari and Mäntysaari (2010), a multiple linear regression model including BW and BW change was used to predict $\mathrm{EB}$ on the first test day. The goodness of EB prediction based on changes in $\mathrm{BW}$ depends on the correctness of the BW measurement. The correctness of the BW and daily BW change measures are also important when the feed efficiency of cows are presented as residual feed energy intake (REI) because the REI is estimated by modeling the total energy intake by energy in milk production, energy needed to maintain BW, and energy needed or released in BW change. In the study of Mäntysaari et al. (2012), a clear effect of stage of lactation was found on REI. It was suggested that this was partly caused by inaccuracy in $\mathrm{BW}$ change measures in the beginning of lactation.

The individual BW measurements of the cow are affected by the udder, gut, and bladder fill. The variation in BW due to milk volume can be minimized by weighing the cows after the milking. If the $\mathrm{BW}$ is measured by the same time of the day and the daily feeding procedure is constant, no big difference in the gut fill would be expected. However, changes, for example in forage batch or weather as well as estrus, can influence the intake of the cow, resulting in changes in gut fill (West, 2003; Huhtanen et al., 2007). This normally occurring variation in after milking $\mathrm{BW}$ of cows with steady body tissue weight is hereafter called random measurement noise. Also, fault or miscalibration of the scale can cause incorrect BW measurements in automatic weighing systems. With daily weighing, one incorrect measurement causes error in 2 consecutive BW change measures. Therefore, it is important to detect and reduce noise in the measurements.

To use BW change as an indicator of EB and in calculation of REI requires frequent BW measurements. The increased popularity of automated weighing systems in commercial farms has made it possible to use BW measurements to estimate energy status but also for other management and diagnostic purposes (Maltz, 1997; van Straten et al., 2009; Frigo et al., 2010; Alawneh et al., 2012). In the study of Frigo et al. (2010), the data from 2 experimental herds showed that selection for reduced BW loss decreased disease incidence in the early stage of lactation. In van Straten et al. (2009), a calculated relative BW loss from daily BW measurements was proposed as a predictor for impaired reproduction performance. Alawneh et al. (2012) presented methods how daily BW monitoring might be used as a tool for early detection of lameness in dairy cattle. Maltz (1997) noticed that approximately $50 \%$ of health problems were identified by BW changes up to
$3 \mathrm{~d}$ before the milk yield drop that set off the health alarm.

One way to handle and minimize the effects of systematic error and random noise in BW measurements is to fit a parametric or time series model into the BW measurements and thereafter use the predicted $\mathrm{BW}$ in calculations. The accuracy of the prediction model is important; a poorly fitting model can even increase the bias. The objectives of this study were to examine the accuracy of different models in predicting $\mathrm{BW}$ of the cows based on daily BW measurements and to investigate the usefulness of modeling in increasing the value of BW measurements as management and breeding tools.

\section{MATERIALS AND METHODS}

\section{Animals and Feeding}

Data were collected during years 2003 to 2004 and 2009 to 2013. The data included 230 Nordic Red dairy cows from the Luke (former MTT Agrifood Research Finland) Minkiö dairy cattle research herd. Of the cows, 177 were primiparous multiple ovulation and embryo transfer nucleus herd test cows and the remaining 53 were multiparous cows. All available daily observations between lactation d 2 to 305 from these cows were included in the data. From the years 2003 to 2004 only the measurements during the indoor feeding period were used, but from years 2009 to 2013 the BW data were included from the pasture season also. In total, the data included 50,594 daily observations with 98,418 individual BW measurements.

All cows were housed in a freestall barn. Cows were milked twice a day (0630 and $1600 \mathrm{~h})$ in a $2 \times 6$ autotandem milking parlor. The cows had ad libitum feeding. During the years 2003 to 2004 cows were fed a TMR containing grass silage and commercial concentrate mix (45-57\% of DM). Feeding of the cows during years 2003 to 2004 is described in detail in Khalili et al. (2006) and Mäntysaari et al. (2006). During the indoor period from 2009 to 2013 all cows were fed grass silage and home blend concentrate mix. The concentrate was given from concentrate feeding stations. The proportion of concentrates in the diet depended on the stage of lactation and the digestibility of the grass silage. When the concentration of digestible organic matter in DM of silage was between 680 to $700 \mathrm{~g} / \mathrm{kg}$ of DM, the concentrates were offered so that the proportion of concentrate in the diet DM became $52 \%$ during lactation $\mathrm{d}$ 1 to $150,47 \%$ during d 151 to 250 , and $37 \%$ thereafter. The amount of concentrate decreased or increased 2 percentage units for each $10 \mathrm{~g} / \mathrm{kg}$ of DM increase or decrease in digestibility of grass silage. Adjustment of the cow's individual concentrate offering was based on 
measured daily silage DM intake of the cow. On average the proportion of concentrate in the diet of all cows in the data was $50.1 \%$.

\section{Measurements and Sampling}

For all cows the individual milk yield and feed intake was recorded daily. However, the feed intakes were not recorded during the pasture period. Milk composition were analyzed once in $2 \mathrm{wk}$ during years 2003 to 2004 and once in $4 \mathrm{wk}$ during years 2009 to 2013. The feed sampling and analysis procedures used during years 2003 to 2004 are explained by Khalili et al. (2006) and Mäntysaari et al. (2006). During years 2009 to 2013, a sample of grass silage for feed analysis was taken twice a week. The subsamples were combined to a 4 -wk sample for analysis. The samples were analyzed for DM, ash, $\mathrm{CP}, \mathrm{NDF}$, quality of silage fermentation, and in vitro OM digestibility. Concentrate samples were collected once a week and combined to give a 6 -wk sample for analysis. The concentrate samples were analyzed for DM, ash, CP, ether extract, and NDF. The analyses of feed samples were performed using procedures previously described by Mäntysaari et al. (2006). The silage was analyzed for pepsin-cellulase solubility and the solubility values were converted to digestible organic matter content in DM (D-values) using different equations for primary and regrowth grass silages according to Huhtanen et al. (2006).

The cows were automatically weighed and BW recorded by walk-through static scale (Pellon Group Oy, Ylihärmä, Finland) on their return from morning and afternoon milking. The BCS of the cows were assessed on a scale of 1 to $5(1=$ skinny to $5=$ very fat $)$ with intervals of 0.25 (Edmonson et al., 1989) every second week during years 2003 to 2004 and every fourth week during years 2009 to 2013.

\section{Data Analyses and Models}

Daily DM and ME intake as well as ECM yield were calculated for each cow. The ME content for grass silage was calculated as $0.016 \times \mathrm{D}$-value $(\mathrm{MAFF}, 1975$, 1984). The ME concentration of the concentrate was calculated from digestible nutrients (MAFF, 1975, 1984). The digestibility coefficients for the components of the concentrates were taken from the Finnish feed tables (MTT, 2013). The daily ME intake was corrected by the total DMI and concentration of ME and protein in the diet according to the correction equation given by MTT (2013).

The ECM yield was calculated according to Sjaunja et al. (1990). To obtain daily BCS, a cubic function on time for each animal was fitted. The daily BCS were predicted from the individual fitted values. The $\mathrm{EB}_{\text {inout }}$ was calculated for each cow by subtracting the energy required for milk and maintenance from the total energy intake. The ME (MJ) used for ECM $\left(\mathrm{ME}_{\text {milk }} \mathrm{MJ}=\right.$ $5.15 \times \mathrm{ECM}, \mathrm{kg})$ and for maintenance $\left(\mathrm{ME}_{\text {maintenance }} \mathrm{MJ}\right.$ $\left.=0.515 \times \mathrm{BW}^{0.75}, \mathrm{~kg}\right)$ were based on the official Finnish requirements (MTT, 2013). The REI was calculated by fitting a multiple linear regression model with energy corrected milk output, metabolic BW $\left(\mathrm{BW}^{0.75}\right)$, and piecewise regressions of BW gain or BW loss on the total energy intake. Thereafter, the daily residuals from the prediction equations were defined to be REI. The effect of gut fill for BW was studied by modeling the BW by DMI. The average of previous and current day DMI $(\mathrm{kg} / \mathrm{d})$ was used as a covariate in the model.

The BW was recorded twice a day. If the difference between morning and afternoon $\mathrm{BW}$ was more than $65 \mathrm{~kg}$ (circa $5 \times$ within-cow SD), the BW measurement that differed more from the BW mean of previous and following day was excluded as an outlier. In total, $2.3 \%$ of individual measurements were either missing or dropped as outliers. Daily average BW was calculated from the daily BW measurements. The standard deviations of weights for morning, afternoon and daily average were 60.1 (73.7), 60.8 (74.4), and 60.2 $\mathrm{kg}(73.7 \mathrm{~kg})$ for first-parity cows (multiparity cows), respectively. The daily average BW were used in the modeling. The cow-wise daily variation in BW and the prediction models for it were estimated using the lmer function of $\mathrm{R}$ program (R Core Team, 2012). The base model was a cow-wise fixed regression model $(\mathbf{F i X})$ by cow and included Wilmink function (Wilmink, 1987) plus a second-order polynomial term. In the Wilmink function, the exponential decay in the beginning of lactation depends on parameter $c$ in $\exp \left(-\mathrm{c}^{*} \operatorname{dim}\right)$. The optimal value for $\mathrm{c}$ was determined by testing all values from $0.01,0.02, \ldots, 0.20$. The value $\mathrm{c}=0.10$ gave the smallest mean squared error (MSE) in overall fixed regression. Thus, the equation for model FiX was

$$
\begin{aligned}
& \mathrm{BW}_{\mathrm{ij}}=\mathrm{f}_{\mathrm{i} 0}+\mathrm{f}_{\mathrm{i} 1} \operatorname{dim}_{\mathrm{j}}+\mathrm{f}_{\mathrm{i} 2} \operatorname{dim}^{2}{ }_{\mathrm{j}} \\
& +\mathrm{f}_{\mathrm{i} 3} \exp \left(-0.10 \times \mathrm{DIM}_{\mathrm{j}}\right)+\varepsilon_{\mathrm{ij}},
\end{aligned}
$$

where $\operatorname{dim}$ is $\mathrm{DIM} / 305$ and $\mathrm{f}_{\mathrm{ik}}, \mathrm{k}=0, \ldots, 3$, are the regression coefficients for the intercept, linear, quadratic, and exponential terms for the cow i, respectively.

The second model was a random regression model with fixed effect of DIM and a random animal part $(\mathrm{MiX})$ :

$$
\begin{gathered}
\mathrm{BW}_{\mathrm{ij}}=\mathrm{b}_{0}+\mathrm{b}_{1} \operatorname{dim}_{\mathrm{j}}+\mathrm{b}_{2} \operatorname{dim}_{\mathrm{j}}^{2} \\
+\mathrm{b}_{3} \exp \left(-0.10 \times \mathrm{DIM}_{\mathrm{j}}\right)+\mathrm{a}_{\mathrm{i} 0}+\mathrm{a}_{\mathrm{i} 1} \operatorname{dim}_{\mathrm{j}}+\mathrm{a}_{\mathrm{i} 2} \operatorname{dim}_{\mathrm{j}}^{2} \\
+\mathrm{a}_{\mathrm{i} 3} \exp \left(-0.10 \times \mathrm{DIM}_{\mathrm{j}}\right)+\varepsilon_{\mathrm{ij}},
\end{gathered}
$$


where dim and DIM are as in model FiX; and $b_{k}, k$ $=0, \ldots, 3$, are the general regression coefficients for the intercept, linear, quadratic, and exponential terms, respectively; and $\mathrm{a}_{\mathrm{ik}}, \mathrm{k}=0, \ldots, 3$, are the corresponding random regression coefficients specific for the cow i. After fitting the models FiX or MiX, the predicted values were used as modeled BW.

The third model (PER) was the model MiX with period of weighing added $(\mathrm{k}=1, \ldots, 13)$. The weighing periods were chosen by first fitting a model MiX with a day of the weighing included. The day effect solutions from the model were then studied from the oldest to the youngest, and the days were retained in a same group as long as their solutions did not deviate from each other more than $20 \mathrm{~kg}$. This yielded 13 time periods of varying lengths. As expected, the months when the cows were in pasture seemed to depart from the mean level. The shortest single period was $14 \mathrm{~d}$ in January 2011, and ended with scale recalibration. After fitting the PER model, the predicted BW were the model predictions but without the period effect.

The fourth and fifth approaches were based on use of natural cubic smoothing splines for weights of each cow individually. In natural cubic spline, the DIM range of each cow is divided into intervals determined by equidistant days, called knots. Next, a third-order polynomial curve (cubic spline) is fitted between these knots. Restrictions are applied to force the curve and its first derivatives to be continuous and for the spline predictions beyond extreme knots to be linear (natural spline). In smoothing splines, the curve coefficients are solved from penalized likelihood. The smoothing parameter $(\lambda)$ determines how much of the variation is explained by the curve. Usually $\lambda$ is estimated using cross validation minimization. We chose to fit the splines with restrictions on smoothing parameters. This way we could keep the orders of the fit comparable with parametrized curves. In the first spline model (SPk8), 8 equally spaced knots were placed into the time range of weighings. In the other spline model (SPdf5), the number of knots was not restricted, but a smoothing of equivalent to 5.0 degrees of freedom was applied to the spline function. Both the spline models were fitted using function smooth.spline in $\mathrm{R}$ program ( $\mathrm{R}$ Core Team, 2012).

\section{Validation of BW Prediction Models}

The daily fitted values from prediction models were subjected to repeated measures model to estimate the average partitioning of variation into variance by cows and into BW changes within each cow. Next, the usefulness of BW prediction models was validated comparing their value in predicting the individual cow EB dur- ing the lactation. The $\mathrm{EB}_{\text {inout }}$, BCS change, and milk fat-protein (FP) ratio were used as measures of EB. As the $\mathrm{EB}_{\text {inout }}$ does not consider the composition of weight changes, the $\mathrm{EB}_{\text {inout }}$ was regressed on the $\mathrm{BW}$ change including simultaneously the BCS change and the gestation stage in the model. The square root of the coefficient of determination $\mathrm{R}^{2}$ of the regression model was considered as validation correlation. The correlations between the change in $\mathrm{BCS}$ and milk $\mathrm{FP}$ ratio to $\mathrm{BW}$ change were also calculated. These validation correlations focused separately on early (wk 4-7), mid (wk 20-23), and late (wk 36-39) lactation.

Finally, the modeled BW were used in an estimation of REI. The REI represent the residual of ME intake after taking into account the energy needs for ECM, maintenance, and BW change. Thus, REI represent the difference between actual and predicted ME intake. The assumption was that the predictors providing the best estimates for $\mathrm{BW}$ and $\mathrm{BW}$ changes are the best in describing the ME intake. The goodness of fit of the $\mathrm{ME}$ intake prediction model with different $\mathrm{BW}$ estimates were compared using the Akaike (AIC) and Bayes (BIC) information criterion values. To illustrate the usefulness of different BW predictors, the squared residuals of ME intake were averaged over cows within lactation wk 1 to 40 separately for primiparous and multiparous cows.

\section{RESULTS}

The average measured BW of the cows was $606 \mathrm{~kg}$, varying from 449 to $837 \mathrm{~kg}$. Primiparous cows were clearly smaller weighing an average of $594 \mathrm{~kg}$, whereas older cows weighed an average of $647 \mathrm{~kg}$ (Table 1). The change in BW during the lactation is presented in Figure 1, where the morning and afternoon BW are plotted as separate lines. The morning BW was an average of $7.3 \mathrm{~kg}$ less than the afternoon BW. The cows lost BW during the first month of lactation after which BW began to increase.

The average ECM yield of the cows was $30.6 \mathrm{~kg} / \mathrm{d}$; for primiparous cows the average yield was $28.4 \mathrm{~kg} / \mathrm{d}$ and for multiparous cows $37.9 \mathrm{~kg} / \mathrm{d}$ (Table 1). Cows ate an average of $19.8 \mathrm{~kg}$ of $\mathrm{DM} / \mathrm{d}$, which corresponded to $232 \mathrm{MJ}$ of ME/d. The patterns of milk yield and DMI during lactation are shown in Figure 2. Figure 2 also presents lactation week averages of $\mathrm{EB}_{\text {inout }}$ (MJ of $\mathrm{ME} / \mathrm{d}$ ) and REI (MJ of ME/d) calculated using measured $\mathrm{BW}$. The $\mathrm{EB}_{\text {inout }}$ was at the lowest during the second week of lactation, and turned positive on the sixth lactation week. During mid- and late lactation, the REI was slightly positive, but clearly negative in early lactation. The development of the BCS and milk FP ratio are presented in Figure 3. The BCS decreased 
Table 1. Mean, standard deviation, and range of ECM production, feed intake, BW, and BCS of cow-wise averages during lactation d 2 to 305

\begin{tabular}{|c|c|c|c|c|}
\hline Item & Mean & $\mathrm{SD}$ & Minimum & Maximum \\
\hline \multicolumn{5}{|c|}{ Primiparous cows $(\mathrm{n}=177)$} \\
\hline ECM, kg/d & 28.4 & 3.24 & 16.2 & 36.2 \\
\hline Milk fat, $\%$ & 4.30 & 0.34 & 3.39 & 5.87 \\
\hline Milk protein, \% & 3.55 & 0.19 & 3.01 & 3.98 \\
\hline Intake, $\mathrm{kg}$ of $\mathrm{DM} / \mathrm{d}$ & 19.1 & 1.88 & 13.4 & 25.4 \\
\hline ME intake, MJ/d & 222 & 22.0 & 154 & 297 \\
\hline $\mathrm{BW}, \mathrm{kg}$ & 594 & 52.8 & 449 & 744 \\
\hline Morning BW, kg & 590 & 52.7 & 445 & 739 \\
\hline Afternoon BW, $\mathrm{kg}$ & 598 & 53.0 & 453 & 750 \\
\hline $\mathrm{BCS}$ & 3.08 & 0.27 & 2.48 & 3.85 \\
\hline \multicolumn{5}{|c|}{ Multiparous cows $(\mathrm{n}=53)$} \\
\hline ECM, kg/d & 37.9 & 5.70 & 25.5 & 52.7 \\
\hline Milk fat, $\%$ & 4.15 & 0.39 & 3.60 & 5.01 \\
\hline Milk protein, $\%$ & 3.38 & 0.22 & 2.88 & 3.78 \\
\hline Intake, $\mathrm{kg}$ of $\mathrm{DM} / \mathrm{d}$ & 22.4 & 1.92 & 18.4 & 27.4 \\
\hline ME intake, MJ/d & 269 & 23.4 & 219 & 328 \\
\hline $\mathrm{BW}, \mathrm{kg}$ & 647 & 69.5 & 534 & 837 \\
\hline Morning BW, kg & 644 & 69.2 & 533 & 831 \\
\hline Afternoon BW, kg & 650 & 69.9 & 535 & 842 \\
\hline BCS & 2.82 & 0.28 & 2.36 & 3.60 \\
\hline \multicolumn{5}{|l|}{ All cows } \\
\hline $\mathrm{ECM}, \mathrm{kg} / \mathrm{d}$ & 30.6 & 5.61 & 16.2 & 52.7 \\
\hline Milk fat, $\%$ & 4.26 & 0.36 & 3.39 & 5.87 \\
\hline Milk protein, $\%$ & 3.51 & 0.21 & 2.88 & 3.98 \\
\hline Intake, $\mathrm{kg}$ of $\mathrm{DM} / \mathrm{d}$ & 19.8 & 2.35 & 13.4 & 27.4 \\
\hline ME intake, MJ/d & 232 & 29.8 & 154 & 328 \\
\hline Body weight, $\mathrm{kg}$ & 606 & 61.1 & 449 & 837 \\
\hline Morning BW, kg & 603 & 61.1 & 445 & 831 \\
\hline Afternoon BW, $\mathrm{kg}$ & 610 & 61.1 & 453 & 843 \\
\hline $\mathrm{BCS}$ & 3.02 & 0.29 & 2.36 & 3.85 \\
\hline
\end{tabular}

during the first 5 wk and thereafter increased slowly. On average, the BCS calculated from cow average data was 3.02 , varying from 2.36 to 3.85 (Table 1 ). The milk FP ratio was the highest at the fifth week of lactation, after which milk FP ratio decreased until wk 22 and stayed quite constant after that.

The pooled residual MSE from the parametric models was the lowest in the PER model (root MSE 9.05

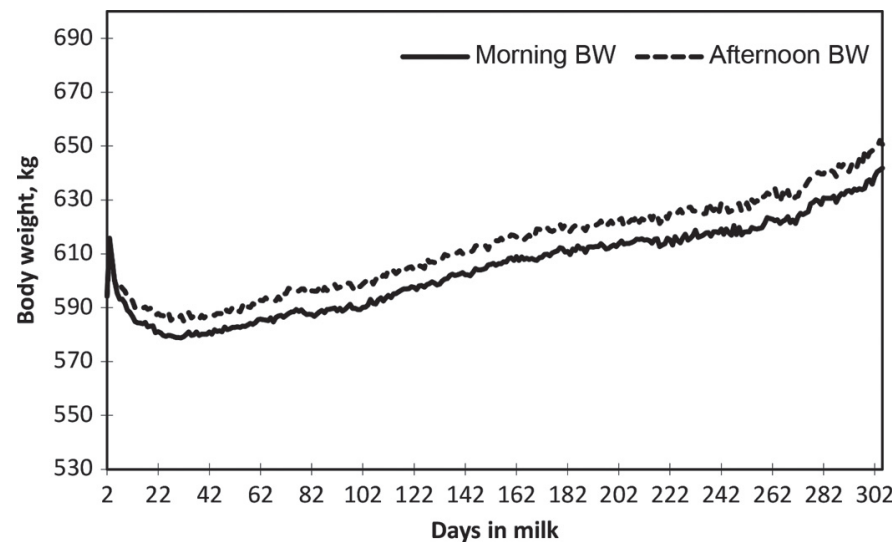

Figure 1. Lactation day averages of morning (around $0700 \mathrm{~h}$ ) and afternoon (around $1700 \mathrm{~h}$ ) BW of the Nordic Red Dairy cows (230 cows). $\mathrm{kg}$ ), followed by FiX model $(10.91 \mathrm{~kg})$ and MiX model $(10.94 \mathrm{~kg})$. Inclusion of periods in the model reduced the unexplained variation in BW by recognizing few obvious scale calibration errors. However, the period effect also removed weight changes related to pasture seasons in 2010, 2011, and 2012. On average, initiation of pasture led to cows losing $36 \mathrm{~kg}$ of $\mathrm{BW}$. The root MSE values for spline functions were lower: 7.30

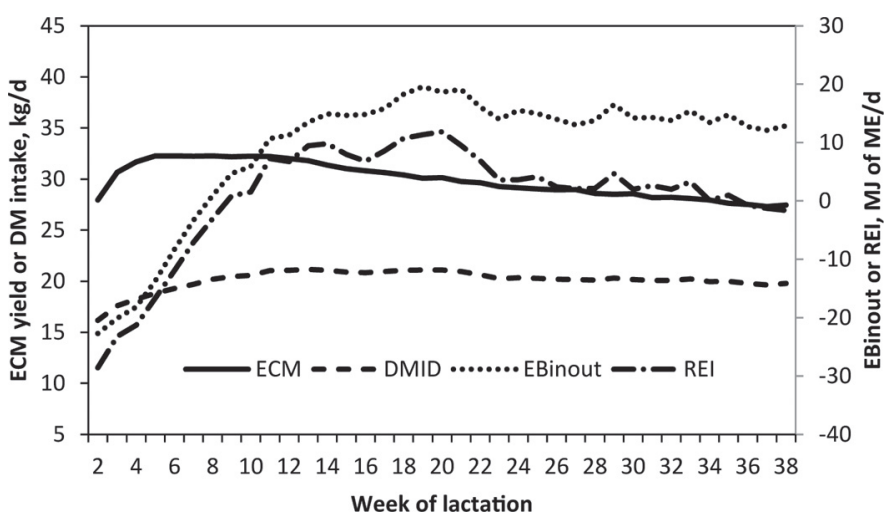

Figure 2. Means of ECM yield, DMI, calculated input-output energy balance (EBinout), and residual energy intake (REI) based on measured BW during lactation of the Nordic Red Dairy cows (230 cows). 


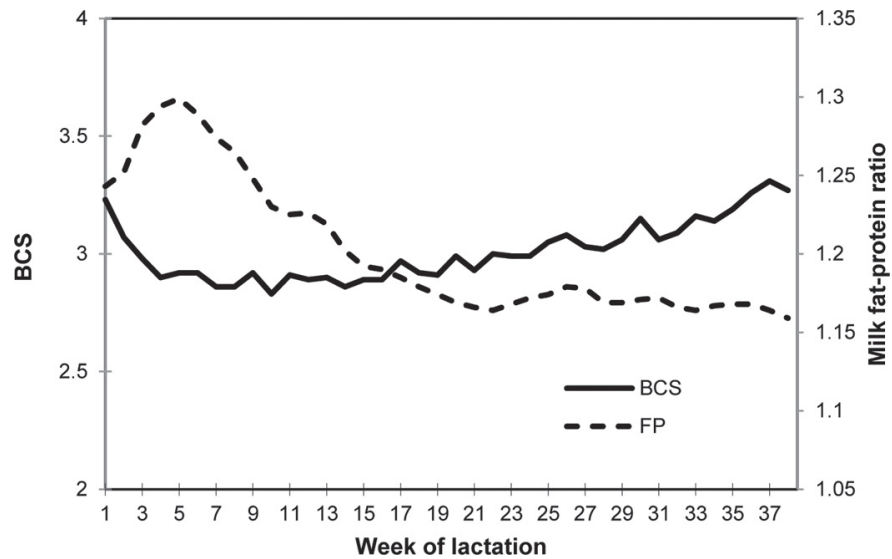

Figure 3. Means of BCS and milk fat-protein ratio (FP) during lactation of the Nordic Red Dairy cows (230 cows).

and 8.86 for $\mathrm{SPk} 8$ and SPdf5 models, respectively. However, these cannot be compared with fit obtained by the parametric functions, because the MSE of the spline functions was restricted by the model description. Similarly, the smallest BIC statistic was with the FiX model (247293.3), followed by PER (366661.8) and MiX models (385292.2), indicating that the model selection cannot be based only on the fit statistics, but more on the usefulness.

Table 2 presents the within-cow standard deviation (standard error; $\mathrm{SE}$ ) and within-cow animal variance as a proportion of total variance $\left(\mathrm{C}^{2}\right)$ for $\mathrm{BW}$ predictions based on different models. As expected, modeling decreased the within cow variance; with measured $\mathrm{BW}$ the $\mathrm{SE}$ and $\mathrm{C}^{2}$ were $16.6 \mathrm{~kg}$ and $6.4 \%$ and with modeled BW 11.2 to $14.7 \mathrm{~kg}$ and 2.9 to $5.1 \%$. Note that the SE for modeled BW are not directly comparable to SE from the raw BW measures. The parametric smoothing removed the daily noise from the predicted values and the $\mathrm{C}^{2}$ merely describes the magnitude of relative range the model function predicts. With the smoothing by splines more of the daily variation remains in the predicted values.

The correlations between BW change based on different models and EB measures on the early, mid, and late lactation are presented in Table 3 . The early lactation includes wk 4 to 7 , mid lactation includes wk 20 to 23 , and late lactation includes wk 36 to 39 . The correlations were higher in early and late lactation than in mid lactation and increased with BW modeling. In the beginning of lactation, the correlation between the original $\mathrm{BW}$ measurements and $\mathrm{EB}_{\text {inout }}$ was only 0.25 , but was over 0.40 with BW based on FiX, MiX, PER, or SPdf5 models. At early lactation, the BW change based on the MiX model gave the highest correlation with the $\mathrm{EB}_{\text {inout }}$. At mid and late lactation, the $\mathrm{BW}$ change based on the FiX models gave as high correlation as the BW change based on the MiX model.

No meaningful correlation existed between the EB indicators, change in BCS and milk FP ratio, and BW change based on original BW recordings. The correlation between modeled BW change and change in BCS was moderate in the beginning of lactation but lower in mid lactation. In late lactation, only the BW change based on FiX and MiX models had notable correlation. The BW change based on MiX, PER, and SPdf5 models had low correlation with milk FP ratio during lactation wk 4 to 7 , but as expected, hardly any correlation was found in the later lactation.

Table 4 lists the model validation statistics of REI estimation model with different BW prediction functions. The smallest BIC and AIC statistics and thereafter the best model fit for the ME intake was achieved when the predicted weights and weight changes from the MiX model were used. All predicted BW gave smaller BIC and AIC statistics than the measured BW no matter which modeling approach was used. Figures 4 and 5 show the lactation week averages of squared daily residuals of $\mathrm{ME}$ intake $\left(\mathbf{R E I}^{2}\right)$ values for primiparous and multiparous cows. For clarity, only the mean squares of $\mathrm{REI}^{2}$ using original BW measures and the predictions from MiX and SPdf5 models are given. With the primiparous cows the $\mathrm{REI}^{2}$ based on MiX model was consistently lower than the $\mathrm{REI}^{2}$ based on any other BW prediction. For multiparous cows the squared REI values based on unmodeled BW were on average highest during wk 1 to 16 , but turned to have a lower average after that.

\section{DISCUSSION}

The increased appearance of automated weighing systems in research farms, but also in commercial

Table 2. Mean, standard deviation (SD), the within-animal standard deviation (SE) and within-animal variance as a proportion of total variance $\left(\mathrm{C}^{2}\right)$ for $\mathrm{BW}$ based on different models during lactation $\mathrm{d}$ $2-305$

\begin{tabular}{lcccc}
$\begin{array}{l}\text { Smoothing } \\
\text { model }^{1}\end{array}$ & Mean & SD & SE & $C^{2}$ \\
\hline None $^{2}$ & 603.3 & 65.9 & 16.6 & 0.064 \\
FiX & 603.3 & 65.0 & 12.6 & 0.038 \\
MiX & 603.3 & 64.9 & 12.4 & 0.037 \\
PER & 603.3 & 66.6 & 11.2 & 0.029 \\
SPk8 & 603.3 & 65.4 & 14.7 & 0.051 \\
SPdf5 & 603.3 & 65.0 & 12.9 & 0.040 \\
\hline
\end{tabular}

${ }^{1} \mathrm{FiX}$ is a cow-wise regression curve with $4 \mathrm{df}$; MiX is a mixed model with cow-wise random random regression effects; PER is MiX model with defined period means; and SPk8 and SPdf5 are cubic smoothing splines with 8 knots and with $5 \mathrm{df}$ penalty function, respectively.

${ }^{2}$ Original measured BW observations. 
MÄNTYSAARI AND MÄNTYSAARI

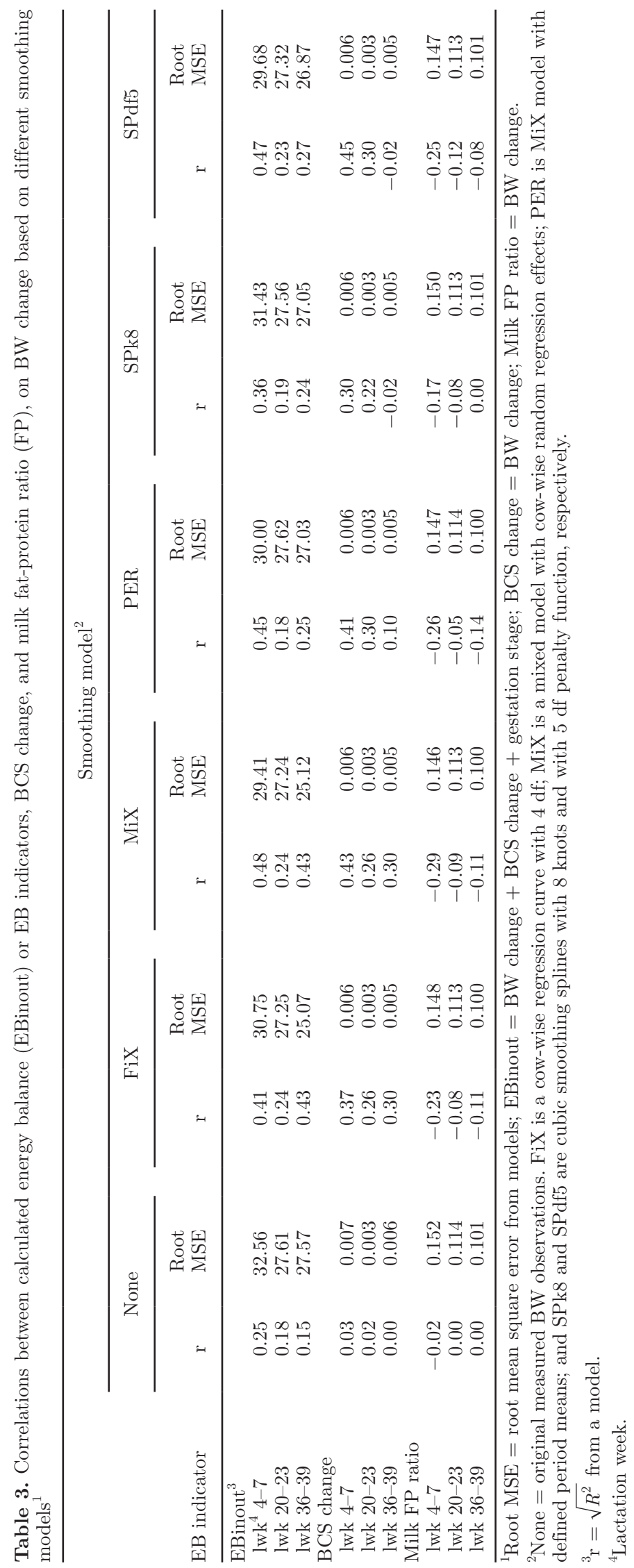




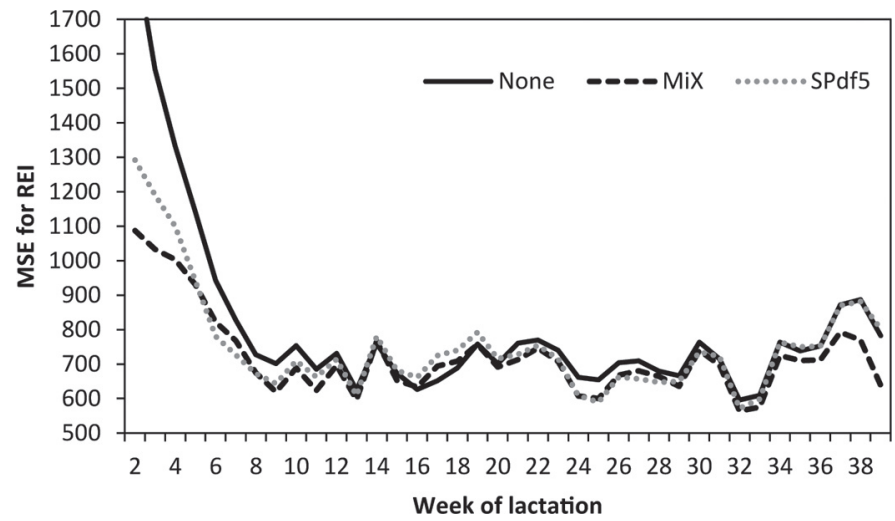

Figure 4. Lactation week means of squared residual ME intake [individual cow daily residual energy intake (REI; MJ of ME /d) $\left.{ }^{2}\right]$ of 177 primiparous Nordic Red cows. The solid line gives the REI ${ }^{2}$ calculated using original BW measures (BW measures), the dashed line is based on BW predictions using mixed random regression model (MiX), and the dotted line is based on natural smoothing splines with 5 degrees of freedom (SPdf5).

farms, has made it possible to record massive amounts of BW data in a short time. The usefulness of the data depends on the reliability of the measures. To get accurate daily $\mathrm{BW}$ measurements is not easy because a single BW measure of a cow is affected by the udder, gut, and bladder fill. As in our data, the effect of milk volume on BW can be minimized by always weighing the cows after milking. In farms with automatic milking systems the weight is often recorded continuously during milking; therefore to get milk-corrected BW, the end weight should be used in calculations as was done in the study of Thorup et al. (2012).

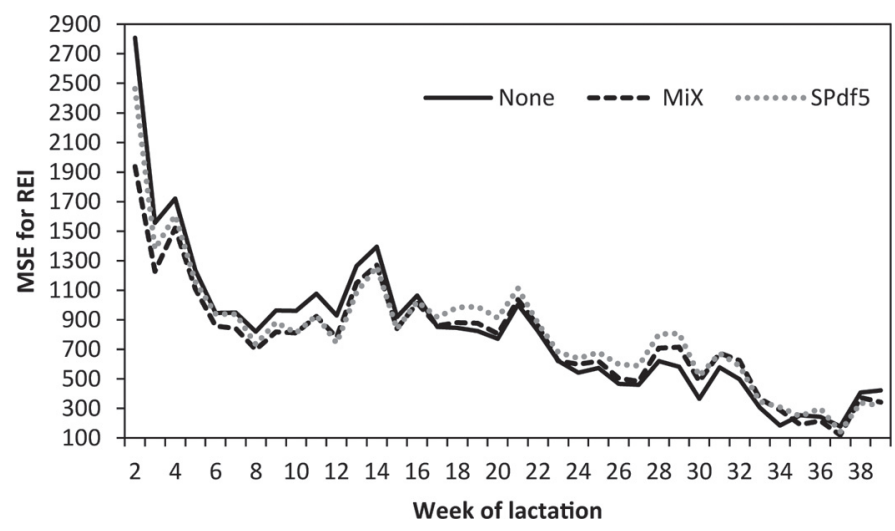

Figure 5. Lactation week means of squared residual ME intake [individual cow daily residual energy intake (REI; MJ of ME/d) ${ }^{2}$ ] of 53 multiparous Nordic Red cows. The solid line gives the REI ${ }^{2}$ calculated using original BW measures (BW measures), the dashed line is based on $\mathrm{BW}$ predictions using mixed random regression model (MiX), and the dotted line is based on natural smoothing splines with 5 degrees of freedom (SPdf5).
Table 4. The model validation statistics for the residual energy intake model when BW and BW changes from different BW-prediction models are used in prediction of daily energy intake

\begin{tabular}{lcc}
$\begin{array}{l}\text { Smoothing } \\
\text { model }^{1}\end{array}$ & $\begin{array}{c}\text { Bayes information } \\
\text { criterion }\end{array}$ & $\begin{array}{c}\text { Akaike information } \\
\text { criterion }\end{array}$ \\
\hline None $^{2}$ & 404937.2 & 404928.6 \\
FiX & 398803.5 & 398794.8 \\
MiX & 398612.4 & 398603.7 \\
PER & 399508.8 & 399500.1 \\
SPk8 & 401815.8 & 401807.1 \\
SPdf5 & 400438.0 & 400429.4 \\
\hline
\end{tabular}

${ }^{1} \mathrm{FiX}$ is a cow-wise regression curve with $4 \mathrm{df}$; MiX is a mixed model with cow-wise random regression effects; PER is MiX model with defined period means; and SPk8 and SPdf5 are cubic smoothing splines with 8 knots and with 5 df penalty function, respectively.

${ }^{2}$ Original measured BW observations.

Our data showed that prerequisite for reliable BW measurements is to always weigh the cows at the same time of the day. The morning (around $0700 \mathrm{~h}$ ) BW was an average $7.3 \mathrm{~kg}$ lower than the afternoon (around $1700 \mathrm{~h}) \mathrm{BW}$. Although feed was available around the clock, it seems that the cows ate more during the daytime than nighttime. In the study of Mäntysaari et al. (2006) it was observed that the cows tended to eat after each delivery of feed. For cows in the current data, the silage or TMR was delivered in the afternoon $2 \mathrm{~h}$ before milking, and in the morning when the cows were in the milking parlor.

Thorup et al. (2012) suggested that the gut fill can be considered as a sum of 2 components. The first is a large meal-related component that is a function of the feed intake pattern in the previous hours, and another, smaller is a residual component remaining in the gut. If the BW is measured by the same time of the day and the feeding procedure is consistent, no big differences in the gut fill should be expected, and thus the residual component can be assumed constant. However, for example changes in forage batch or weather and estrus can affect the intake of the cow resulting changes in gut fill (West, 2003; Huhtanen et al., 2007). To address the errors rising from feeding patterns, we examined the effect of gut fill on BW by modeling the BW by the DMI. Including the DMI in the model decreased the within-cow variation in BW from 6.4 to $5.3 \%$ of the total variance. Thus, if DMI information are available, correcting the BW measures with DMI may somewhat decrease the random measurement noise. Alternatively the effect of gut fill can be accounted by calculating an empty BW. Different equations including DMI and diet energy concentration have been developed to calculate gut fill. We tested the empty BW calculation using the equations given by Chilliard et al. (1991), Komaragiri and Erdman (1997), and Coffey et al. (2001). With these alternative equations the within cow variation in 
empty BW were $6.4,5.2$, and $7.5 \%$ of total variance, respectively.

Beside gut fill, bladder fill also can affect the individual BW measurement of the cow. However, its effect cannot be significant because on average the total daily urine excretion is about 20 to $30 \mathrm{~kg}$ (Bannink et al., 1999; Nennich et al., 2006) and the urination frequency about 10 times a day (Bannink et al., 1999).

Random errors and fluctuations in BW measurements can be decreased by modeling the BW measurements. In the current study the fitted BW models differed in utilization of information. In the FiX model approach, each individual is modeled separately. Similarly, the spline-based smoothing operates cow by cow. This is useful because each animal can be analyzed separately without need for other data. On the other hand, the models FiX and SPk8 work differently for animals with different length of measuring period. In the shortest intervals, the animal could have only $8 \mathrm{~d}$ of data, and the SPk8 or FiX would not smooth the weight curve much. The suitability of these models for diagnosing weight loss soon after calving is therefore limited. The spline model SPdf5 uses more or all observation days as knots, but limits the model fit to similar level as the spline with 8 knots. Indicated by lower root MSE, the spline with 8 knot parameterization followed the observations closer than the smoothing based on 5 degrees of freedom (root MSE $=7.30 \mathrm{~kg}$ vs. $8.66 \mathrm{~kg}$ ). The latter seemed to give more usable predictions for short time windows as was indicated by good validation results in the beginning of lactation. At the end of the lactation, SPdf5 was not comparative with parametric models FiX and MiX, which suggests that the smoothing penalty was not severe enough.

The MiX model estimates the average variation among cows and uses the estimated variances to shrink the estimates of cow-wise regression coefficients closer to zero and thereafter the weight predictions toward the across cow average BW curve. In other words, the random regression model weighs the individual animal information against information from all animals. The variance components pertaining to cow-wise regression coefficients and daily measurement error can be estimated in advance. Then the cow-wise regressions will predict BLUP of the weight change curves. In principle the MiX model approach requires availability of BW measures of all animals or at least representative sample because these will contribute to the general mean regression curve. If the mean regression is estimated beforehand, the individual cow BW curve can be estimated cow by cow. The cow-wise prediction can be called approximate selection index approach (Henderson, 1984).
The difference of MiX and PER models was on estimation of mean level of the BW. The PER model attempts to account non-animal-related weight changes such as errors in scale calibration. However, if the period to period change in $\mathrm{BW}$ is related to true weight change in the whole herd, the PER model removes erroneously such change from the predictions. The modeling of systematic changes could be improved by inclusion of weighing related independent factors into the BW model. However, because one of the interests for the weight data is its use in management decisions, the value of historic data is questionable. Thus, although the PER model had apparently better fit than the MiX model, its usability for prediction of weight change has limitations.

If the $\mathrm{BW}$ is measured unbiased, the change in $\mathrm{BW}$ should describe the energy status of the cow. Therefore the change in BW can be used as an EB indicator (Coffey et al., 2001; Friggens et al., 2007; Mäntysaari and Mäntysaari, 2010; Thorup et al., 2012). We addressed the relation of $\mathrm{EB}_{\text {inout }}$ and the $\mathrm{BW}$ change based on BW from different models together with change in BCS and gestation stage. The inclusion of change in BCS accounted for the differences in energy value of the BW change. The gestation stage effect separated the energy required for pregnancy and growth of the cow. The energy utilization for a growing fetus is known to be lower than for BW gain (Ferrell et al., 1976). It was clear that the BW modeling increased the usability of the BW measurements. Of all the tested models, the MiX model gave the highest correlations with $\mathrm{EB}_{\text {inout }}$ in the beginning, mid, and late lactation.

In all the cases the correlations between $\mathrm{EB}_{\text {inout }}$ and modeled BW change were only moderate. This can, however, be explained by the limitations of the $\mathrm{EB}_{\text {inout }}$. In calculation of $\mathrm{EB}_{\text {inout, }}$ considerable errors can rise from a use of standard estimates for requirements. Between cows, differences can be present in digestion (Berry et al., 2007) and utilization of ME for separate functions. According to the study of Yan et al. (2006) and the reviews of Veerkamp and Emmans (1995) and Agnew and Yan (2000), it is unlikely that a large difference exists between cows in the efficiency of use of ME for production. However, because of differences in milk composition, some differences may occur. Chwalibog (1991) reported the partial efficiency of ME utilization for fat energy deposition in milk to be 0.82 and for protein and carbohydrates energy in milk 0.54 . The production capacity of the cows can also affect the energy requirements for maintenance; the high producing cows have a bigger mass of active organs (liver, heart), which increases the maintenance requirements (DiCostanzo et al., 1990). 
To avoid the mentioned problems concerning the $\mathrm{EB}_{\text {inout }}$ calculation, the $\mathrm{BW}$ change based on different models were also evaluated by using the change in BCS or milk FP ratio as indicators of cow's energy status instead of $\mathrm{EB}_{\text {inout. }}$. In the beginning of lactation the use of body reserves results in decrease in BCS and in the late lactation, when the reserves are restored, the BCS increases (Mäntysaari and Mäntysaari, 2010). The changes in body reserves should lead also to corresponding changes in BW. In our data no correlation between $\mathrm{BW}$ changes based on original measurements and BCS change was found, but using modeled BW the correlation was moderate. In early lactation, BW change based on MiX and SPdf5 models had the highest correlations with BCS change. In mid lactation, the BW change based on PER and SPdf5models had higher correlation than the MiX model BW prediction. However, the change in BCS during wk 9 to 30 of lactation was only minimal and therefore no correlation was expected. In the case of milk FP ratio, no correlation with measured BW change was found and with modeled BW change notable correlation was measured only in the beginning of lactation. It has been shown that the milk FP ratio reflects the energy status of the cow in early lactation, but not in later lactation (Buttchereit et al., 2010; Mäntysaari and Mäntysaari, 2010). Thus, if the weight models are judged by milk FP ratio, only the relationship during the first weeks can be taken into consideration. On wk 4 to 7 , based on the correlations, the MiX model gave the most trustworthy BW predictions. Based on our findings, it seems that from all tested models the MiX model gave the most reliable prediction for the BW.

The different BW models were evaluated also by the fit of ME intake model. With accurate estimates of energy intake, ECM yield, BW, and BW change, and no big differences in the digestion or utilization of ME for separate functions between cows, we should be able to predict the ME intake well, and the residual, REI, should be close to null. The increase in accuracy of any of the parameters, including the $\mathrm{BW}$ and the $\mathrm{BW}$ change, should improve the fit of the model. According to BIC and AIC modeling of BW in the current data increased the fit of model. Again, the highest fit was with BW predicted by MiX model. Similarly as with $\mathrm{EB}_{\text {inout }}$ the independent variables in $\mathrm{ME}$ intake model can never describe the ME intake perfectly, because of noise in all measures, but also because of natural variation among cows (Mäntysaari et al., 2012). The mean $\mathrm{REI}^{2}$ in Figures 4 and 5 illustrates not only the precision of the measures but also the biological variation. The elevated level of mean of $\mathrm{REI}^{2}$ in the first $4 \mathrm{wk}$ after calving is largely caused by difficulties in modeling of weight loss, but also will suggest the presence of more differences between cows in early lactation. The daily variation in REI at the end of lactation was much smaller. It has to be noted that the original BW measures gave lower average $\mathrm{REI}^{2}$ than modeled BW after $30 \mathrm{wk}$ in lactation for multiparous cows. This is likely a result of overmodeling, for example due to the effect of occasionally seen large DMI affecting both measured BW and energy intake.

\section{CONCLUSIONS}

Based on our validation results, the value of modeled BW change as a predictor of EB was much higher than the weight gain or loss estimated from measured daily BW. The highest correlation between the tested weight change prediction models and EB measures was with a mixed linear model that included individual cow random regression functions. The advantage of prediction models over measured BW was the highest in the beginning of lactation, but the parametric smoothing models MiX and FiX did maintain moderate correlations with $\mathrm{EB}$ measures and $\mathrm{BW}$ change predictions even at the end of lactation. Also, the smoothing spline model based on 5 degrees of freedom predicted $\mathrm{BW}$ well in the beginning of lactation but was worse than parametric models of the end of lactation. We also estimated the daily individual REI with the modeled BW and measured BW. The fit estimated as model statistics (BIC and AIC) was better for modeled BW. The mean squared residual ME intake was on average smaller with modeled BW, indicating better accuracy, especially during the first 4 wk of lactation.

\section{ACKNOWLEDGMENTS}

This study is a part of larger project on feed utilization on Nordic cattle (FUNC). The project involves researchers and research herds from Natural Resources Institute Finland (Luke); Helsinki University; Swedish University of Agricultural Sciences (SLU), Sweden; Aarhus University, Denmark; and Norwegian University of Life Sciences. The Finnish part of the study is partly funded by Finnish Ministry of Agriculture, Valio Ltd. (Helsinki, Finland), Faba Co-op (Vantaa, Finland), VikingGenetics (Randers, Denmark), Suomen Naudanjalostussäätiö (Finland), and Raisioagro Ltd. (Raisio, Finland), which is greatly appreciated.

\section{REFERENCES}

Agnew, R. E., and T. Yan. 2000. Impact of recent research on energy feeding systems for dairy cattle. Livest. Prod. Sci. 66:197-215.

Alawneh, J. I., M. A. Stevenson, N. B. Williamson, N. Lopez-Villalobos, and T. Otley. 2012. The effect of clinical lameness on 
liveweight in a seasonally calving, pasture-fed dairy herd. J. Dairy Sci. 95:663-669.

Bannink, A., H. Valk, and A. M. van Vuuren. 1999. Intake and excretion of sodium, potassium and nitrogen and the effects on urine production by lactating dairy cows. J. Dairy Sci. 82:1008-1018.

Berry, D. P., B. Horan, M. O'Donovan, F. Buckley, E. Kennedy, M McEvoy, and P. Dillon. 2007. Genetics of grass dry matter intake, energy balance and digestibility in grazing Irish dairy cows. J. Dairy Sci. 90:4835-4845.

Buttchereit, N., E. Stamer, W. Junge, and G. Thaller. 2010. Evaluation of five lactation curve models fitted for fat:protein ratio of milk and daily energy balance. J. Dairy Sci. 93:1702-1712.

Chilliard, Y., M. Cisse, R. Lefaivre, and B. Remond. 1991. Body composition of dairy cows according to lactation stage, somatotropin treatment and concentrate supplementation. J. Dairy Sci. 74:3103-3116

Chwalibog, A. 1991. Energetic efficiency of milk production in Jersey cows. J. Anim. Physiol. Anim. Nutr. (Berl.) 65:206-218.

Coffey, M. P., G. C. Emmans, and S. Brotherstone. 2001. Genetic evaluation of dairy bulls for energy balance traits using random regression. Anim. Sci. 73:29-40.

Collard, B. L., P. J. Boettcher, J. C. M. Dekkers, D. Petitclerc, and L. R. Schaeffer. 2000. Relationships between energy balance and health traits of dairy cattle in early lactation. J. Dairy Sci. 83:2683-2690.

de Vries, M. J., S. van der Beek, L. M. T. E. Kaal-Lansbergen, W. Ouweltjes, and J. B. Wilmink. 1999. Modeling of energy balance in early lactation and the effect of energy deficits in early lactation on first detected estrus postpartum in dairy cows. J. Dairy Sci. 82:1927-1934

DiCostanzo, A., J. C. Meiske, S. D. Plegge, T. M. Peters, and R. D. Goodrich. 1990. Within-herd variation in energy utilization for maintenance and gain in beef cows. J. Anim. Sci. 68:2156-2165.

Edmonson, A. J., I. J. Lean, L. D. Weaver, T. Farver, and G. Webster. 1989. A body condition scoring chart for Holstein dairy cows. J. Dairy Sci. 72:68-78.

Ferrell, C. L., W. N. Garrett, and N. Hinman. 1976. Growth, development and composition of the udder and gravid uterus of beef heifers during pregnancy. J. Anim. Sci. 42:1477-1489.

Friggens, N. C., C. Ridder, and P. Løvendahl. 2007. On the use of milk composition measures to predict the energy balance of dairy cows. J. Dairy Sci. 90:5453-5467.

Frigo, E., C. Dechow, O. Pedron, and B. G. Cassell. 2010. The genetic relationship of body weight and early-lactation health disorders in two experimental herds. J. Dairy Sci. 93:1184-1192.

Henderson, C. R. 1984. Application of Linear Models in Animal Breeding. University of Guelph, Canada.

Huhtanen, P., J. Nousiainen, and M. Rinne. 2006. Recent developments in forage evaluation with special reference to practical applications. Agric. Food Sci. 15:293-323.

Huhtanen, P., M. Rinne, and J. Nousiainen. 2007. Evaluation of the factors affecting silage intake of dairy cows: A revision of the relative silage dry-matter intake index. Animal 1:758-770.

Khalili, H., P. Mäntysaari, J. Sariola, and R. Kangasniemi. 2006. Effect of concentrate feeding strategy on the performance of dairy cows fed total mixed ration. Agric. Food Sci. 15:269-279.

Koenen, E. P. C., A. F. Groen, and N. Gengler. 1999. Phenotypic variation in live weight and live-weight changes of lactating HolsteinFriesian cows. Anim. Sci. 68:109-114.
Komaragiri, M. V. S., and R. A. Erdman. 1997. Factors affecting body tissue mobilization in early lactation dairy cows. 1. Effects of dietary protein on mobilization of body fat and protein. J. Dairy Sci. 80:929-937.

MAFF. 1975. Energy allowances and feeding systems for ruminants. In: Ministry of Agriculture, Fisheries and Food Technical Bulletin, No. 33. Ministry of Agriculture, Fisheries and Food, London, UK.

MAFF. 1984. Energy allowances and feeding systems for ruminants. In ADAS Reference Book, No. 433. Ministry of Agriculture, Fisheries and Food, London, UK.

Maltz, E. 1997. The body weight of the dairy cow: III. Use for on-line management of individual cows. Livest. Prod. Sci. 48:187-200.

Mäntysaari, P., H. Khalili, and J. Sariola. 2006. Effect of feeding frequency of a total mixed ration on the performance of high-yielding dairy cows. J. Dairy Sci. 89:4312-4320.

Mäntysaari, P., A.-E. Liinamo, and E. A. Mäntysaari. 2012. Energy efficiency and its relationship with milk, body and intake traits and energy status among primiparous Nordic Red dairy cattle. J. Dairy Sci. 95:3200-3211

Mäntysaari, P., and E. A. Mäntysaari. 2010. Predicting early lactation energy balance in primiparous Red Dairy Cattle using milk and body traits. Acta Agric. Scand. A Anim. Sci. 60:79-87.

MTT. 2013. Feed tables and nutrient requirements. MTT Agrifood Research Finland, Jokioinen. Accessed Jun. 1, 2014. http://www. mtt.fi/feedtables.

Nennich, T. D., J. H. Harrison, L. M. VanWieringen, N. R. St-Pierre, R. L. Kincaid, M. A. Wattiaux, D. L. Davidson, and E. Block. 2006. Prediction and evaluation of urine and urinary nitrogen and mineral excretion from dairy cattle. J. Dairy Sci. 89:353-364.

R Core Team. 2012. R: A Language and Environment for Statistical Computing. Vienna, Austria. http://www.R-project.org.

Sjaunja, L. O., L. Baevre, I. Junkkarinen, J. Pedersen, and J. Setälä. 1990. A nordic proposal for an energy corrected milk (ECM) formula. Pages 156-157 in Proc. 27th Session of International Committee of Recording and Productivity of Milk Animal, Paris France.

Thorup, V. M., D. Edwards, and N. C. Friggens. 2012. On-farm estimation of energy balance in dairy cows using only frequent body weight measurements and body condition score. J. Dairy Sci 95:1784-1793.

van Straten, M., N. Y. Shpigel, and M. Friger. 2009. Associations among patterns in daily body weight, body condition scoring and reproductive performance in high-producing dairy cows. J. Dairy Sci. 92:4375-4385.

Veerkamp, R. F., and G. C. Emmans. 1995. Sources of genetic variation in energetic efficiency of dairy cows. Livest. Prod. Sci. 44:8797.

West, J. W. 2003. Effects of heat-stress on production in dairy cattle. J. Dairy Sci. 86:2131-2144.

Wilmink, J. B. M. 1987. Adjustment of test-day milk, fat and protein yield for age, season and stage of lactation. Livest. Prod. Sci $16: 335-348$

Yan, T., C. S. Mayne, T. W. J. Keady, and R. E. Agnew. 2006. Effects of dairy cow genotype with two planes of nutrition on energy partitioning between milk and body tissue. J. Dairy Sci. 89:1031-1042. 